Article

\title{
Study of 13Cr-4Ni-(Mo) (F6NM) Steel Grade Heat Treatment for Maximum Hardness Control in Industrial Heats
}

\author{
Massimo De Sanctis ${ }^{1, *}$, Gianfranco Lovicu ${ }^{2}$, Massimiliano Buccioni ${ }^{2}$, Angelo Donato ${ }^{2}$, \\ Maria Richetta ${ }^{3}$ and Alessandra Varone ${ }^{3}$ \\ 1 Dipartimento di Ingegneria Civile e Industriale, Università di Pisa, Largo Lucio Lazzarino, 2, \\ 56122 Pisa, Italy \\ 2 Nuovo Pignone Tecnologie Srl, BHGE, Via Felice Matteucci, 2, 50127 Firenze, Italy; \\ gianfranco.lovicu@bhge.com (G.L.); Massimiliano.Buccioni@bhge.com (M.B.); \\ Angelo.Donato@bhge.com (A.D.) \\ 3 Dipartimento di Ingegneria Industriale, Università di Tor Vergata, Via del Politecnico, 1, 00133 Roma, \\ Italy; richetta@uniroma2.it (M.R.); alessandra.varone@uniroma2.it (A.V.) \\ * Correspondence: m.desanctis@ing.unipi.it; Tel.: +39-050-2217827
}

Received: 16 June 2017; Accepted: 31 August 2017; Published: 6 September 2017

\begin{abstract}
The standard NACE MR0175 (ISO 15156) requires a maximum hardness value of 23 HRC for $13 \mathrm{Cr}-4 \mathrm{Ni}-(\mathrm{Mo})$ steel grade for sour service, requiring a double tempering heat treatment at temperature in the range $648-691{ }^{\circ} \mathrm{C}$ for the first tempering and $593-621^{\circ} \mathrm{C}$ for the second tempering. Difficulties in limiting alloy hardness after the tempering of forged mechanical components (F6NM) are often faced. Variables affecting the thermal behavior of $13 \mathrm{Cr}-4 \mathrm{Ni}-(\mathrm{Mo})$ during single and double tempering treatments have been studied by means of transmission electron microscopy (TEM) observations, X-ray diffraction measurements, dilatometry, and thermo-mechanical simulations. It has been found that relatively low $\mathrm{Ac}_{1}$ temperatures in this alloy induce the formation of austenite phase above $600{ }^{\circ} \mathrm{C}$ during tempering, and that the formed, reverted austenite tends to be unstable upon cooling, thus contributing to the increase of final hardness via transformation to virgin martensite. Therefore, it is necessary to increase the $\mathrm{Ac}_{1}$ temperature as much as possible to allow the tempering of martensite at the temperature range required by NACE without the detrimental formation of virgin martensite upon final cooling. Attempts to do so have been carried out by reducing both carbon $(<0.02 \% \mathrm{C})$ and nitrogen $(<100 \mathrm{ppm})$ levels. Results obtained herein show final hardness below NACE limits without an unacceptable loss of mechanical strength.
\end{abstract}

Keywords: supermartensitic stainless steels; tempering treatments; austenite reversion

\section{Introduction}

Low-carbon supermartensitic stainless steel $13 \mathrm{Cr}-4 \mathrm{Ni}-(\mathrm{Mo})$ has substituted $12 \% \mathrm{Cr}$ for several decades, and more recently, CA15 steels in many applications in the oil/gas industry [1,2]. The combination of low carbon content with the addition of $3.5-4.5 \% \mathrm{Ni}$ suppresses the formation of $\delta$-ferrite and promotes the formation of a mixed structure of $\alpha^{\prime}$ (martensite) and $\gamma$ (austenite) at room temperature, which possesses superior mechanical properties and corrosion resistances [3-5]. This alloy is proposed in two delivery conditions: casted (CA6NM) or forged (F6NM), and it finds wide applications for handling fluids containing $\mathrm{CO}_{2}$ and $\mathrm{H}_{2} \mathrm{~S}$. These environments increase the danger of sulfide stress corrosion cracking (SSCC); the NACE MR0175 standard limits 13Cr-4Ni alloys to $23 \mathrm{HRC}$ maximum for sour service. However, in industrial practice, considerable difficulties are faced in lowering the hardness of $13 \mathrm{Cr}-4 \mathrm{Ni}-(\mathrm{Mo})$ below $23 \mathrm{HRC}$. These difficulties are of crucial interest, since tempering 
treatments are carried out on expensive mechanical components (e.g., compressor rotors) in their final state. Tempering should maximize the recovery of the martensitic matrix and promote the retention of soft retained austenite at room temperature. Previous studies on the thermal behavior of low-carbon 13Cr-4Ni alloy [2] and 16Cr-5Ni-(Mo) [6] showed that the amount of retained austenite increases with increasing reversion treatment temperature, exhibiting a peak typically in the range $620-640{ }^{\circ} \mathrm{C}$. Above this range, it decreases with increasing temperatures, leading to the formation of virgin martensite upon cooling, with increasing hardness. It has been suggested that the stability of reversed austenite initially increases because of the diffusion of nickel and other gamma-stabilizing elements from the martensitic matrix towards reverted austenite islands [7-9]. Above a critical tempering temperature, a gradual loss of stability would occur because of several factors, among which the most important seems to be the solute redistribution for increasing volume fractions of reversed austenite [10]. The NACE MR0175 standard requires a double tempering treatment after quenching for F6NM, with a tempering temperature within $650-690{ }^{\circ} \mathrm{C}$ for the first tempering and $595-620{ }^{\circ} \mathrm{C}$ for the second one. An initial high-temperature treatment which is even higher than the $\mathrm{Ac}_{1}$ temperature of the alloy will favor softening of as-quenched martensite, and at the same time, the formation of reverted austenite, which can at least partially transform into virgin martensite upon cooling. The aim of the second stage of tempering is the recovery of the newly formed virgin martensite. Experimental diagrams are available for $13 \mathrm{Cr} 4 \mathrm{Ni} 0.5 \mathrm{Mo}$ [11], giving the final hardness and content of retained austenite at room temperature as a function of temperature and time of tempering treatments using a "Larson-Miller"-type parameter $\left(P=T(\mathrm{~K})[20+\log t(\mathrm{~h})] \times 10^{-3}\right)$. For $13 \mathrm{Cr} 4 \mathrm{Ni} 0.5 \mathrm{Mo}$ after single heat treatment, most reverted austenite formed up to $P=17.7$ is expected to remain stable while cooling to room temperature, and according to these data sets, hardness would attain a minimum of $250 \mathrm{HB}$. Double treatments are indicated as effective in reducing hardness around $220 \mathrm{HB}$ - at least when the second tempering is carried out below $P=18.2$. Nevertheless, from industrial experience and previous indications, there is a considerable scatter of results with related economic losses.

Gooch [12] studied the effects of heat treatments for welded $13 \mathrm{Cr} 4 \mathrm{Ni}$ steels, and agreed on the difficulty in limiting the alloy hardness through post-weld heat treatments. He concluded that the major compositional factor determining hardness was carbon, which should be limited below $0.03 \%$. The objective of this work is to carry out a detailed study on microstructural transformations occurring during single and double temper treatments of $13 \mathrm{Cr} 4 \mathrm{Ni}(\mathrm{Mo})$ steel, with the aim of clarifying the compositional and microstructural variables influencing the final hardness of this alloy and to give useful guidelines for industrial practice.

\section{Materials and Methods}

Two industrial heats of $13 \mathrm{Cr} 4 \mathrm{Ni} 0.5 \mathrm{Mo}$ have been considered in this work, with chemical compositions reported in Table 1.

Table 1. Chemical composition of the studied alloys.

\begin{tabular}{|c|c|c|c|c|c|c|c|c|c|c|}
\hline Heats & $\% \mathrm{C}$ & $\% S i$ & $\% M n$ & $\% P$ & $\% \mathrm{Cr}$ & $\%$ Mo & $\% S$ & $\% \mathrm{Ni}$ & $\mathbf{N}($ ppm) & $\% \mathrm{Cr}_{\mathrm{eq}} / \% \mathrm{Ni}_{\mathrm{eq}}$ * \\
\hline A & 0.027 & 0.35 & 0.90 & 0.019 & 12.89 & 0.52 & 0.001 & 3.84 & 180 & 2.45 \\
\hline B & 0.030 & 0.44 & 0.73 & 0.018 & 12.72 & 0.55 & 0.001 & 3.85 & 280 & 2.35 \\
\hline
\end{tabular}

The compositions are very close, with an almost coincidental $\mathrm{Cr}_{\mathrm{eq}} / \mathrm{Ni}_{\mathrm{eq}}$ ratio. The only significant differences are the higher carbon $(0.03 \% \mathrm{C})$ and nitrogen $(280 \mathrm{ppm})$ contents in Heat B than in Heat A (0.027\% C, 180 ppm N).

These industrial heats were processed through the following treatments:

- $\quad$ Homogenizing at $1473 \mathrm{~K}\left(1200^{\circ} \mathrm{C}\right)$ for $4 \mathrm{~h}$, followed by preliminary hot forging (HR);

- $\quad$ Intermediate stress relief at $700{ }^{\circ} \mathrm{C}$; 
- $\quad$ Forging (F samples) at $1473 \mathrm{~K}\left(1200^{\circ} \mathrm{C}\right)$;

- $\quad$ Austenitizing $4 \mathrm{~h}$ at $1020^{\circ} \mathrm{C}$ followed by oil quenching (OQ) to room temperature.

The $\mathrm{Ac}_{1}$ and Ms critical temperatures were determined by dilatometric analysis using a Gleeble 3800 thermo-mechanical simulator (Dynamic Systems Inc., Poestenkill, NY, USA), equipped with a ISO-Q Quenching and Deformation Dilatometer. The samples were heated at $1020^{\circ} \mathrm{C}$, with a heating rate of $300{ }^{\circ} \mathrm{C} / \mathrm{h}$, held for $1 \mathrm{~h}$ at the target temperature, and then cooled to room temperature using different cooling rates of 100 and $3000{ }^{\circ} \mathrm{C} / \mathrm{h}$. Volume variations of samples were measured by a laser dilatometry system [13]. Figure 1 shows the geometry and dimensions of the samples used. Details of the experimental technique are reported elsewhere [14].

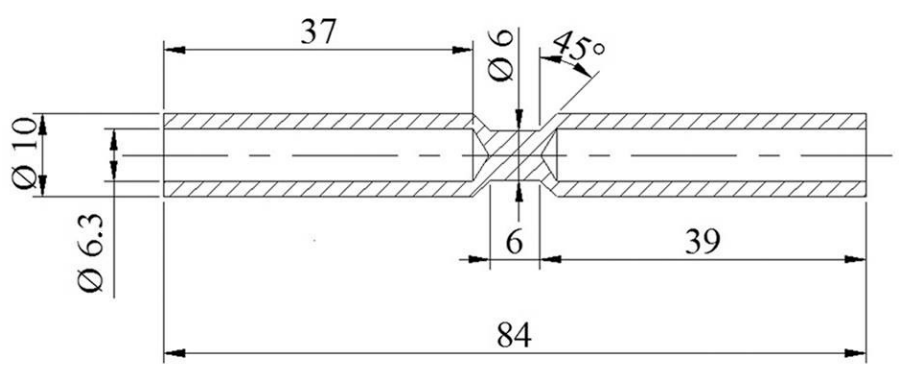

Figure 1. Geometry of the sample used for dilatometric analysis (unit: $\mathrm{mm}$ ).

The Gleeble ${ }^{\circledR} 3800$ simulator has also been used to reproduce single and double tempering treatments in the temperature range $610-700{ }^{\circ} \mathrm{C}$ using heating rates of $300{ }^{\circ} \mathrm{C} / \mathrm{h}$ with holding times of $1 \mathrm{~h}$ followed by air cooling. Treated samples have been used to determine their mechanical properties. The volume fraction of retained austenite at room temperature $\left(\gamma_{\mathrm{r}}\right)$ was determined by $\mathrm{X}$-ray diffraction (Philips, Eindhoven, The Netherlands). XRD spectra were collected in the $2 \theta$ angular range $5^{\circ}$ to $65^{\circ}$ by using the Mo-K $\alpha$ radiation $\left(\lambda=0.71 \AA\right.$ ) in step scanning mode with steps of $0.05^{\circ}$ and counting time of $5 \mathrm{~s}$ per step. The relative amounts of martensite and retained austenite were calculated for each sample from the integrated intensities of the reflections of both phases, following the ASTM E975 standard [15].

Mechanical properties were measured by means of tensile tests on a Galdabini ${ }^{\circledR}$ SUN 1000 tensile machine (Cardano al Campo (VA), Italy). Tensile specimens which were $1 \mathrm{~mm}$ in thickness, $12.5 \mathrm{~mm}$ in width, and with a gage length of $50 \mathrm{~mm}$, heat treated by Gleeble 3800 as described above have been used. Tests were performed using a crosshead displacement rate of $1 \mathrm{~mm} / \mathrm{s}$, and the gage length elongation was measured using an extensometer. To compare the quantity of austenite in the microstructure of samples subjected to different quenching and tempering treatments, the instantaneous strain-hardening coefficient $(n)$ was evaluated. It is defined as follows:

$$
n=\frac{d(\ln \sigma)}{d(\ln \varepsilon)}
$$

where $\sigma$ and $\varepsilon$ are true stress and true strain, respectively.

The presence of the austenitic phase-with its associated high work hardening behavior-induces high $n$ values and pronounced plateau in the $n$ vs. true strain curves, depending on its volume fraction and stability. Moreover, it is also responsible for the observed marked serration in the instantaneous strain hardening curves [16].

Microstructural studies have been carried out by transmission electron microscopy (TEM) using a Philips ${ }^{\circledR}$ CM12 microscope (Philips Electron Optics, Eindhoven, The Netherlands) equipped with a Bruker ${ }^{\circledR}$ Quantax TEM 200T EDX system (Bruker, Berlin, Germany). Thin foils were prepared by mechanical grinding followed by double-jet electropolishing in a solution of $10 \%$ perchloric acid and $90 \%$ butoxyethanol at $258 \mathrm{~K}\left(-15^{\circ} \mathrm{C}\right)$ and $9 \mathrm{~V}$. 
Alloy hardness was measured using Rockwell (Hardness tester, C.I.S.A.M. sas, Induno Olona, Italy) tests from industrial byproducts and Vickers (Micro-hardness tester, Shimadzu Corporation, Kyoto, Japan) tests from $1 \mathrm{~mm}$-thick heat-treated samples used in the Gleeble 3800 simulator. The Vickers hardness scale is frequently used for these heats for weld procedure qualification tests, and according to the BS860 1967 standard, a $23 \mathrm{HRC}$ limit would be equivalent to $253 \mathrm{HV}$. It has been shown that this conversion-as well as the ASTM E140-88 correlation-is not applicable to $13 \mathrm{Cr}-4 \mathrm{Ni}$-(Mo) materials, with several researchers indicating $23 \mathrm{HRC}$ as equivalent to $275 \mathrm{HV}[17,18]$. Therefore, this hardness equivalence will be used hereinafter.

\section{Results}

Table 2 compares the hardness values of preliminary hot forged (HR) and as-quenched (after forging) (OQ) samples from different heats. In spite of their similar chemical compositions, hot rolled samples are very different in hardness, with Heat A ( $31.1 \pm 1.0$ HRC) being significantly harder than Heat B $(25.1 \pm 0.8$ HRC $)$.

Table 2. Hardness of Heats A and B in hot rolled (HR) and oil quenched (OQ) conditions.

\begin{tabular}{ccc}
\hline \multirow{2}{*}{ Heat } & \multicolumn{2}{c}{ Hardness (HRC) } \\
\cline { 2 - 3 } & HR-Samples & As-Quenched Samples \\
\hline A & $31.1 \pm 1.0$ & $35.3 \pm 1.3$ \\
B & $25.1 \pm 0.8$ & $34.2 \pm 1.2$ \\
\hline
\end{tabular}

The hardness difference was partially recovered in OQ samples where Heat B ( $34.2 \pm 1.2 \mathrm{HRC})$ showed about the same hardness as Heat A ( $35.3 \pm 1.3 \mathrm{HRC})$. Considering that the hardness value is also affected by the amount of retained austenite, the Ms-Mf range for Heat A is expected to be higher in temperature than for Heat B.

The $\mathrm{Ms}$ and $\mathrm{Ac}_{1}$ critical temperatures have been determined through dilatometric analysis, and relevant experimental curves for Heat $A$ and Heat $B$ are reported in Figure 2.

The experimental $\mathrm{Ac}_{1}$ temperatures for Heats $\mathrm{A}$ and $\mathrm{B}$ were calculated from the dilatometric curves and by analyzing their derivatives. Figure 3 shows the derivative curves in the range of temperature close to the transformation point. Three different curves have been considered, performed at different cooling rates (two samples at $100{ }^{\circ} \mathrm{C} / \mathrm{h}$ and one at $3000{ }^{\circ} \mathrm{C} / \mathrm{h}$ ), but with the same heating rate $\left(300{ }^{\circ} \mathrm{C} / \mathrm{h}\right)$. For the same Heat, there is a good agreement among the $\mathrm{Ac}_{1}$ temperatures determined from different samples. The uncertainty of calculated $A_{1}$ was determined using the temperature range in which it is possible to verify the slope change of dilatometric curves and their derivatives.

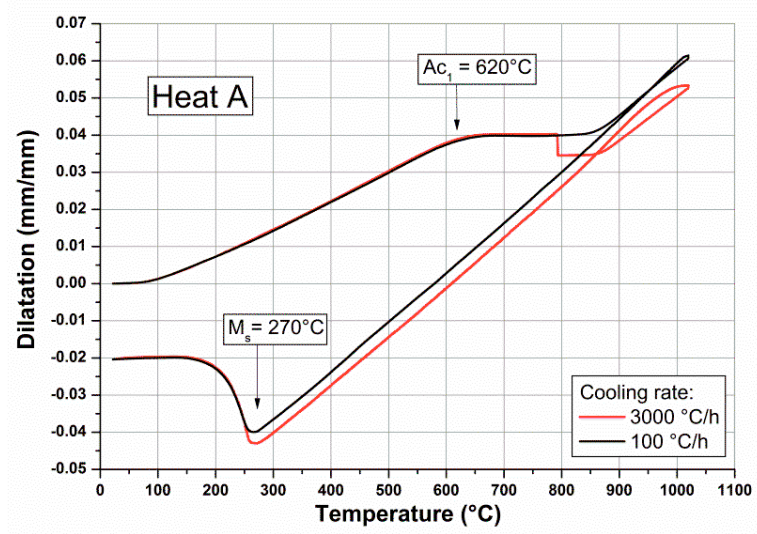

(a)

Figure 2. Cont. 


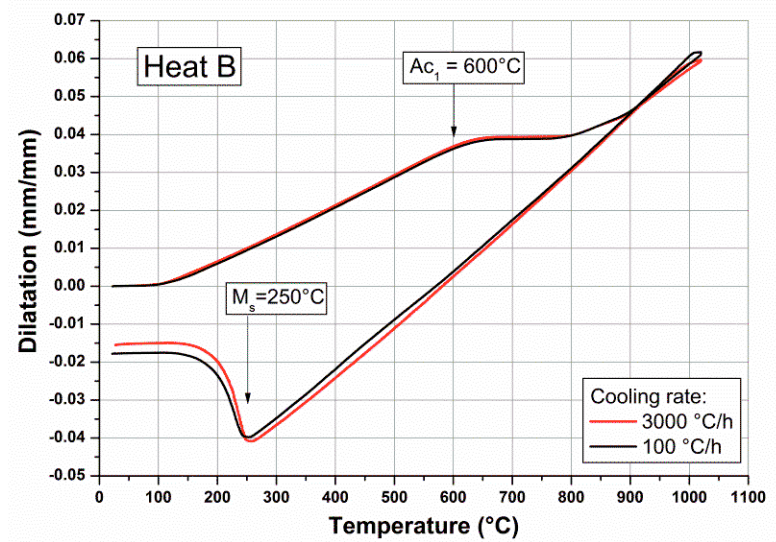

(b)

Figure 2. Dilatometric curves of (a) Heat A and (b) Heat B.

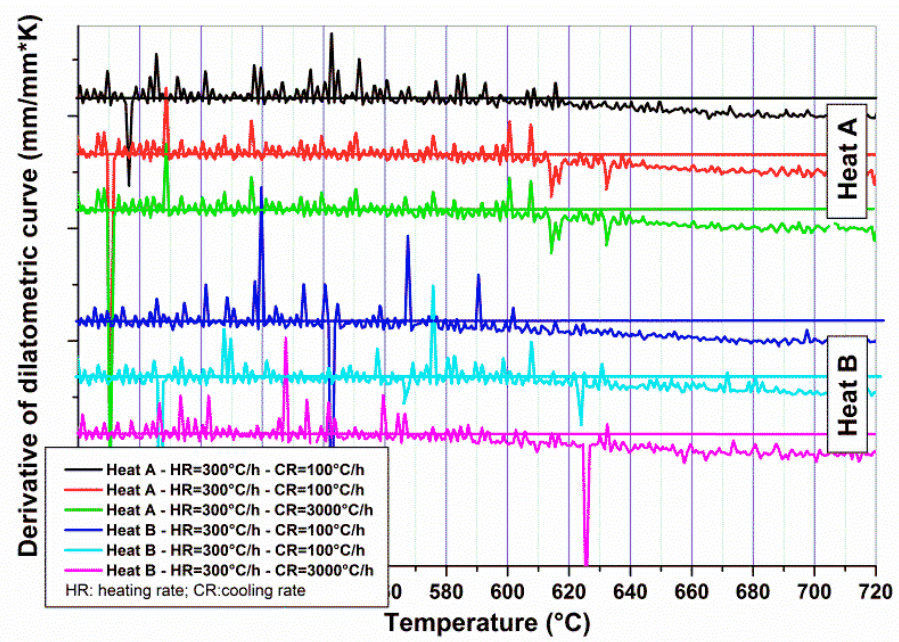

Figure 3. Derivatives of dilatometric curves of Heat A and Heat B samples. Different curves have been shifted to avoid overlapping and to allow a better comparison among them.

$\mathrm{Ac}_{1}$ temperatures for Heat $\mathrm{A}$ and $\mathrm{B}$ were around $620 \pm 10$ and $600 \pm 10^{\circ} \mathrm{C}$, respectively. These results could be compared to the calculated $\mathrm{Ac}_{1}$ temperature for $13 \% \mathrm{Cr}$ steels having carbon contents lower than $0.05 \%[19]$, according to the following formula:

$$
\mathrm{Ac}_{1}\left({ }^{\circ} \mathrm{C}\right)=850-1500(\mathrm{C}+\mathrm{N})-50 \mathrm{Ni}-25 \mathrm{Mn}+25 \mathrm{Si}+25 \mathrm{Mo}+20(\mathrm{Cr}-10)
$$

The predicted $\mathrm{Ac}_{1}$ temperature for Heats $\mathrm{A}$ and $\mathrm{B}$ were 647 and $633^{\circ} \mathrm{C}$, respectively. These values are higher than the experimental temperature, although it is confirmed that the $\mathrm{Ac}_{1}$ temperature of Heat $A$ is higher with respect to Heat $B$.

The Ms temperature for Heat $\mathrm{B}\left(250 \pm 10^{\circ} \mathrm{C}\right)$ is lower than Heat $\mathrm{A}\left(270 \pm 15^{\circ} \mathrm{C}\right)$, thus supporting the propensity for this alloy to retain higher volume fractions of austenite in $\mathrm{HR}$ and OQ products.

Figure 4 shows electron micrographs from OQ samples of Heat A and Heat B. The microstructures consist of an $\alpha^{\prime}$ martensite matrix, in which fine and highly dislocated laths are distributed parallel to one another. The presence of retained austenite is not evident in OQ state, being scarcely visible only in Heat B in the form of thin interlath films (Figure $4 b$ ).

Figure 5 shows stress-strain curves and Figure 6 yield strength (YS) and ultimate tensile strength (UTS) values obtained on OQ samples heat treated (tempered) by Gleeble 3800 for one hour at different temperatures in the temperature range $610-700{ }^{\circ} \mathrm{C}$. 

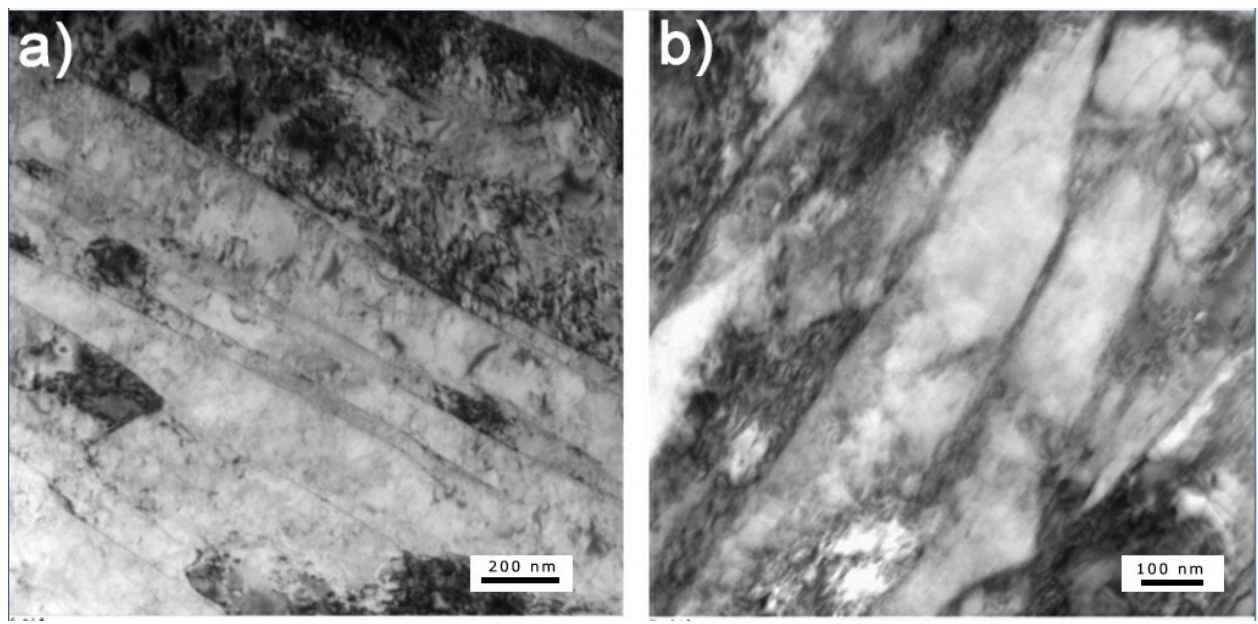

Figure 4. TEM electron micrographs of (a) Heat A and (b) Heat B after oil quenching (OQ samples).

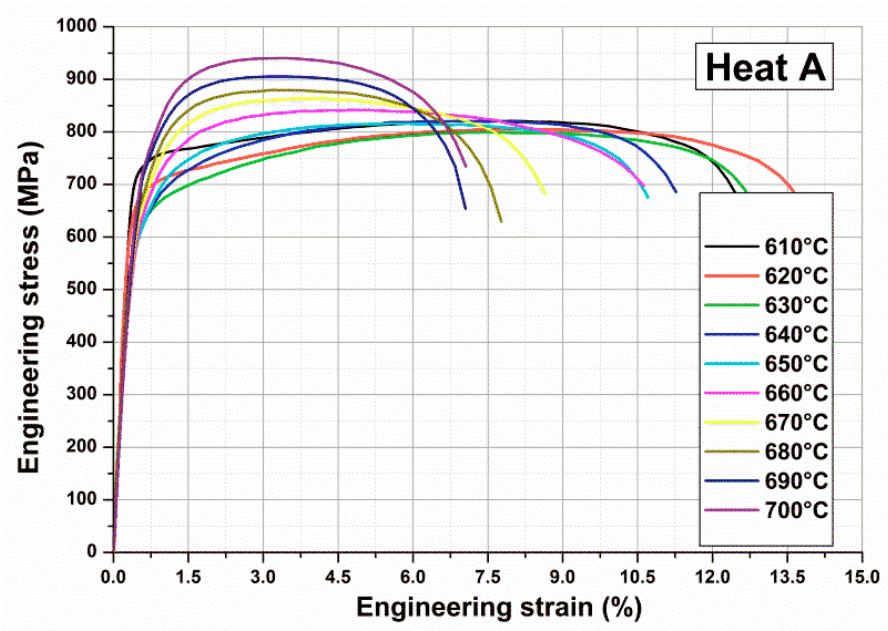

(a)

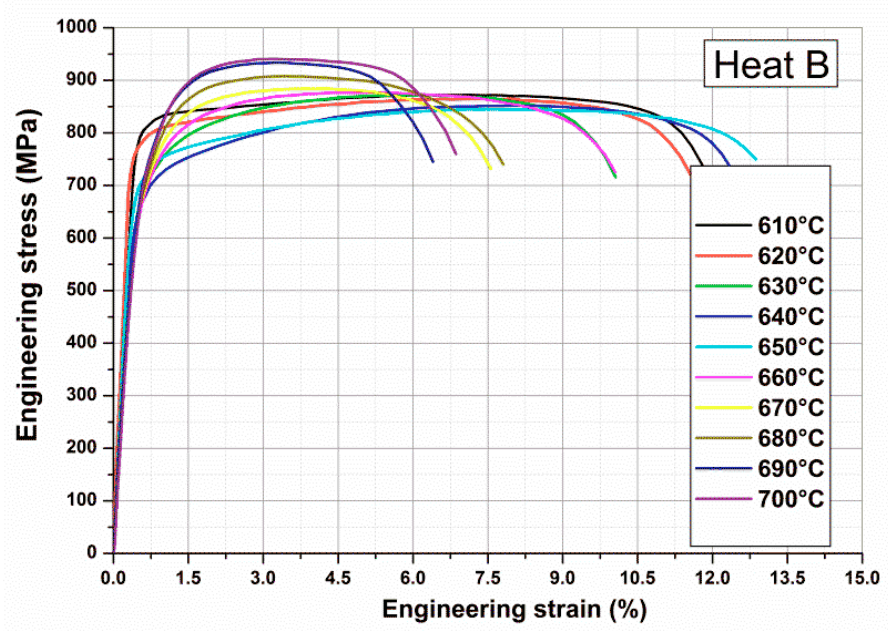

(b)

Figure 5. Experimental stress-strain curves of (a) Heat A and (b) Heat B after single tempering at different temperatures. 


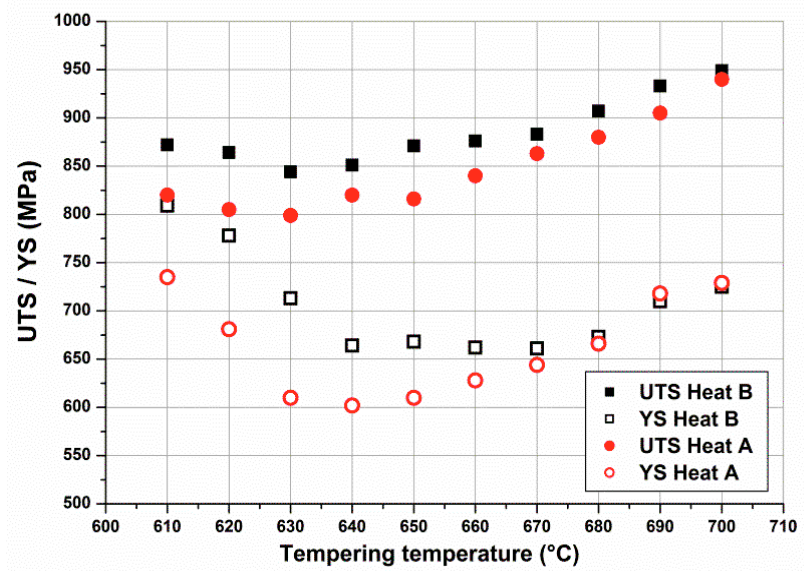

Figure 6. Yield (YS) and tensile (ultimate tensile strength, UTS) strengths of Heat A (red) and Heat B (black) after single tempering at different temperatures $\left(610-700{ }^{\circ} \mathrm{C}\right)$.

The Vickers hardness (HV10) measurements of these samples are shown in Figure 7. It can be observed that Heat B remained constantly harder than the limit of 275 HV (23 HRC), whereas the hardness reduction of Heat A allowed values close to the limit. Moreover, for both heats there was a slight decrease of strengths and hardness when increasing the tempering temperature from 610 to around $650{ }^{\circ} \mathrm{C}$, followed by a step increase for higher temperatures.

Figure 8 shows volume fractions of retained austenite measured in Heat A and Heat B after single tempering. The austenite content of both heats was relatively low, with the values consistently below $10 \%$. For Heat B the peak was reached at $630^{\circ} \mathrm{C}$, whereas for Heat A it was around $640{ }^{\circ} \mathrm{C}$.

Strength and hardness were reduced in the presence of retained austenite, but they showed a further increase when austenite disappeared, as shown in Figure 6. This was also confirmed by the instantaneous strain hardening coefficient, $n$, measured during tensile tests of single tempered samples, as shown in Figure 9. This coefficient is sensitive to all factors influencing the strain hardening behavior of the steel. For steels whose microstructure is a mixture of martensite and austenite, both the mean value and the punctual variability of $n$ were affected by relative amounts of soft retained austenite. As shown in Figure 9, the gradual loss of stability of reverted austenite for tempering temperatures above $640^{\circ} \mathrm{C}$ in Heat $\mathrm{A}$ is apparent, with a practical absence of retained austenite at room temperature for tempering treatments above $670{ }^{\circ} \mathrm{C}$.

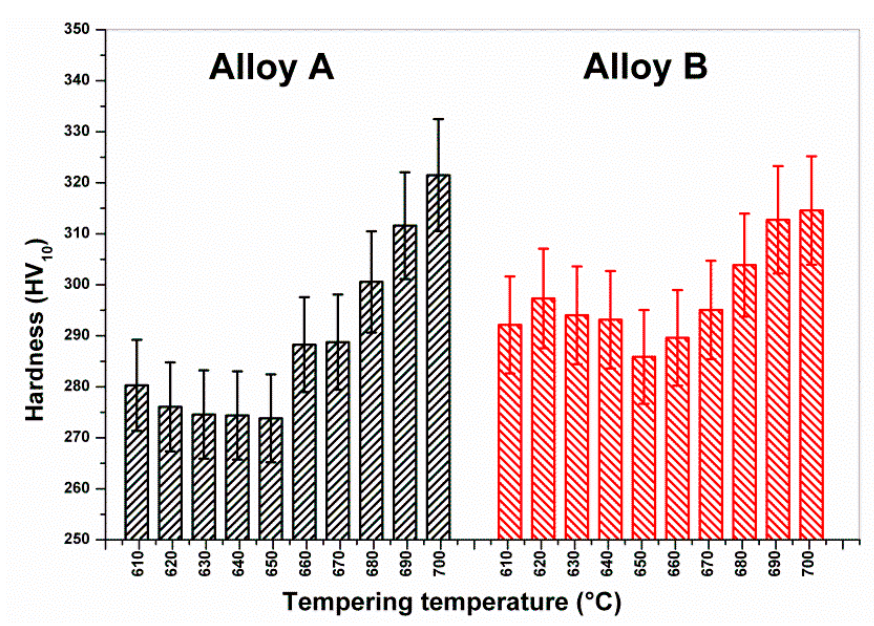

Figure 7. Hardness values for Heat A and Heat B as a function of the single tempering treatment. 


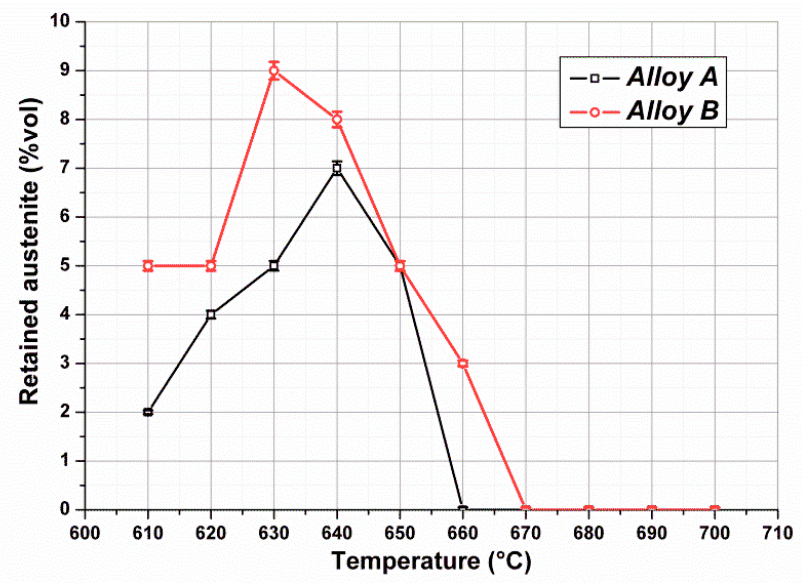

Figure 8. Volume fraction of retained austenite in function of tempering temperatures.

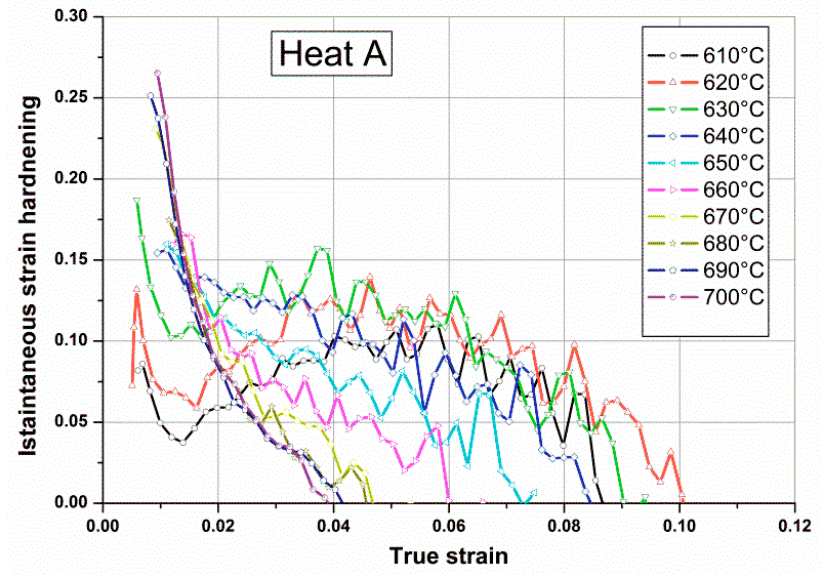

Figure 9. Instantaneous strain hardening coefficient of Heat A after different tempering treatments.

From these results, the final hardness after single tempering appears to be the result of both the structural recovery of untempered martensite and the relative stability of reverted austenite during previous heating. Strength and hardness initially decreased after single tempering above $600{ }^{\circ} \mathrm{C}$ due to increased recovery of as-quenched martensite and the retention of stable retained austenite. For increasing temperatures, reverted austenite became unstable, forming virgin martensite upon cooling, thus determining a further increase of both hardness and strength.

Figure 10 shows the microstructure of Heat $\mathrm{A}$ after single tempering at $620^{\circ} \mathrm{C}$ (Figure 10a) and $680^{\circ} \mathrm{C}$ (Figure 10b), respectively, below and above the critical temperature for austenite destabilization upon cooling. The microstructure of samples tempered at $620^{\circ} \mathrm{C}$ consisted of tempered martensite with elongated islands of retained austenite formed in the interlath regions with no evidence of untempered martensite. After tempering at $680^{\circ} \mathrm{C}$, many islands of highly dislocated virgin martensite were observed.

Finally, Figure 11 shows the alloy microstructure after tempering at $650{ }^{\circ} \mathrm{C}$, where all possible structural constituents may coexist—specifically, recovered original martensite, virgin martensite, and retained stable austenite.

As shown in Figure 11 and Table 3, image contrast coupled with energy-dispersive X-ray spectroscopy (EDS) measurements can be conveniently used to distinguish between different constituents. Regions where $\alpha^{\prime}$ to $\gamma$ reversion occurred are characterized by an increased amount of both $\mathrm{Ni}$ and $\mathrm{Mn}$ compared to the nominal heat composition, as a consequence of solute redistribution between phase constituents during tempering. 

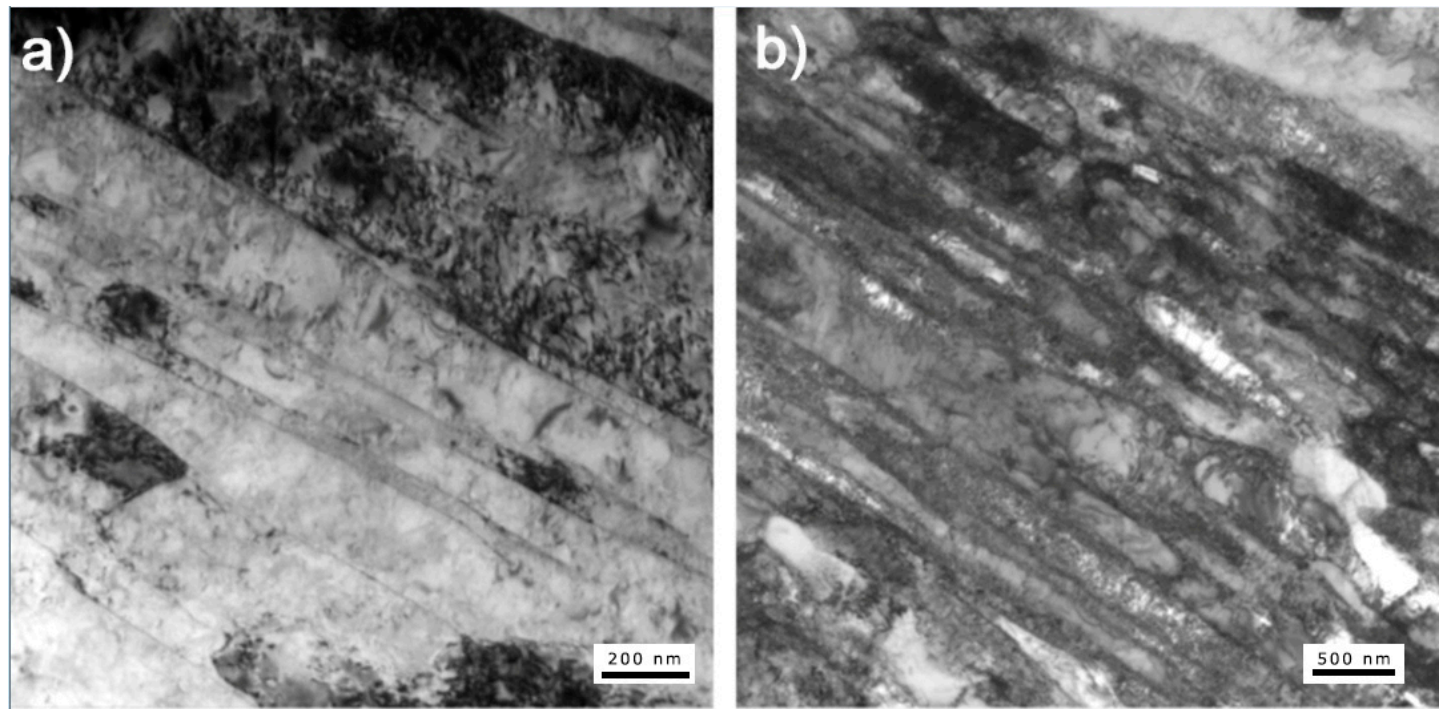

Figure 10. TEM electron micrographs of Heat A after single tempering treatment at: (a) $620^{\circ} \mathrm{C}$ and (b) $680{ }^{\circ} \mathrm{C}$

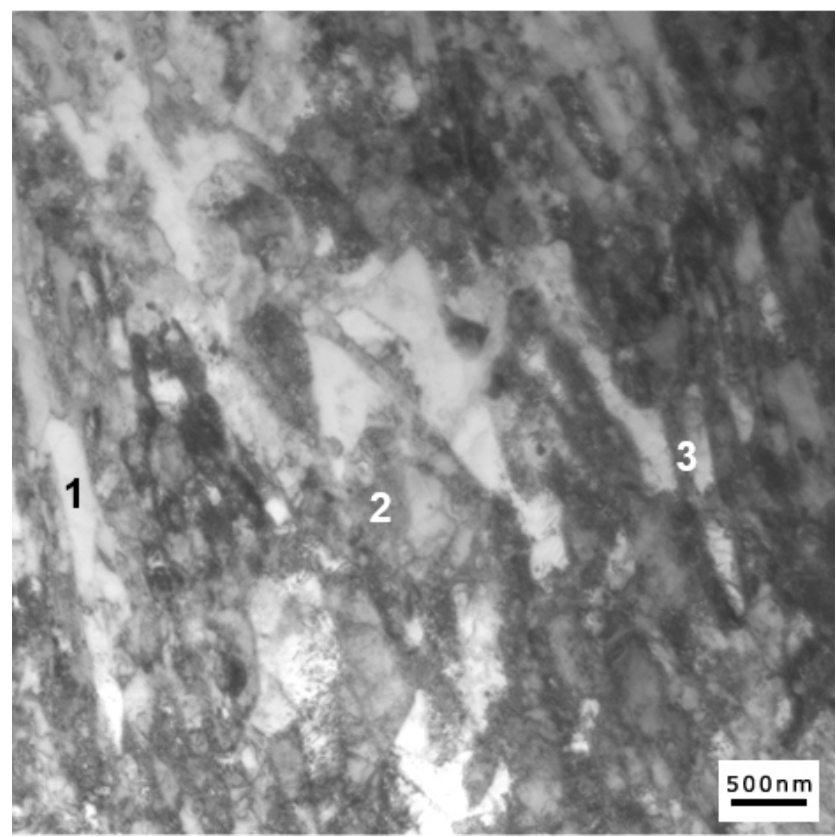

Figure 11. TEM micrograph of Heat A tempered at $650{ }^{\circ} \mathrm{C}$. Numbers in the figure identify the regions where Energy dispersive X-ray EDX microanalysis was performed. Results for $\mathrm{Cr}$, $\mathrm{Mn}$, and Ni weight percentages are reported in Table 3.

Table 3. Content of $\mathrm{Cr}, \mathrm{Mn}$, and Ni measured by EDX microanalysis from the different regions marked in Figure 11.

\begin{tabular}{cccc}
\hline Region Marked in Figure 11 & wt \% Cr & wt \% Mn & wt \% Ni \\
\hline 1 (retained austenite) & $12.47 \pm 0.5$ & $2.40 \pm 0.2$ & $7.32 \pm 0.3$ \\
2 (tempered martensite) & $13.57 \pm 0.4$ & $0.76 \pm 0.1$ & $3.30 \pm 0.2$ \\
3 (virgin martensite) & $13.16 \pm 0.7$ & $1.99 \pm 0.3$ & $5.07 \pm 0.2$ \\
\hline
\end{tabular}


Among these areas, retained austenite islands can be further distinguished by a low density of dislocations (Figure 11, Region 1), in contrast to virgin martensite with a high density of dislocations (Figure 11, Region 3). Finally, regions of tempered martensite are characterized by decreased nickel content compared to the nominal heat composition, as well as by partial recovery of the martensitic matrix (Figure 11, Region 2).

The effect of a second tempering treatment was investigated, taking into consideration NACE recommendations for the first cycle (for which NACE requires a temperature in the range $648-690{ }^{\circ} \mathrm{C}$ ); two temperatures corresponding to the presence or total absence of stable austenite were chosen: $650{ }^{\circ} \mathrm{C}(P=18.4)$ and $680{ }^{\circ} \mathrm{C}(P=19.0)$, respectively. For the second cycle, the minimum and maximum NACE-recommended temperatures-595 ${ }^{\circ} \mathrm{C}(P=17.3)$ and $620^{\circ} \mathrm{C}(P=17.9)$-were used. Figure 12 shows YS and UTS, and Figure 13 shows the hardness after double tempering.

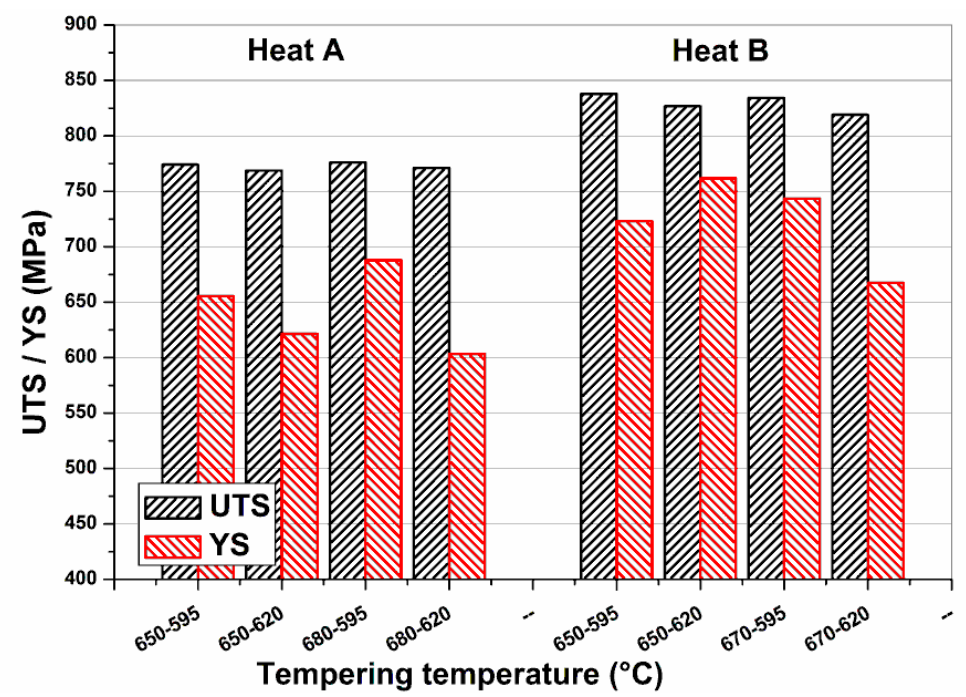

Figure 12. YS and UTS of Heat A and Heat B following double temper treatments.

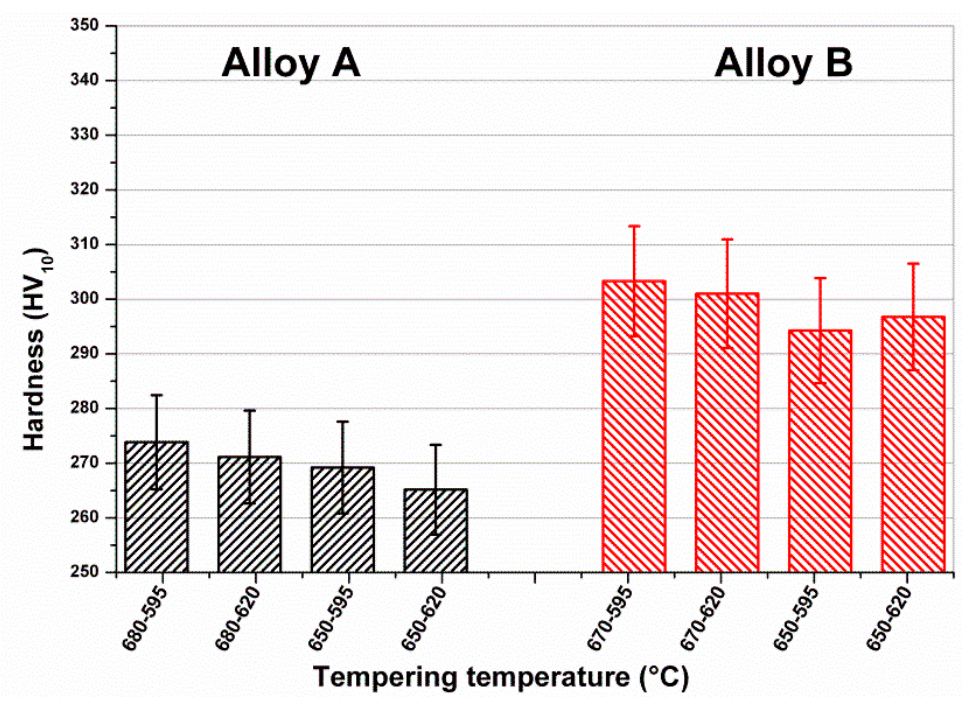

Figure 13. Hardness values for Heat A and Heat B in function of double tempering treatments.

Both tensile strength and hardness levels were significantly lower compared to the first tempering cycle, with hardness reduced to $266 \mathrm{HV}$ after $1 \mathrm{~h}$ at $650{ }^{\circ} \mathrm{C}$, and $1 \mathrm{~h}$ at $620^{\circ} \mathrm{C}$, whereas no useful reductions were obtained for Heat $\mathrm{B}$, with tensile strengths above $800 \mathrm{MPa}$, with hardness values remaining around $300 \mathrm{HV} 10$. 
The effects of intermediate and final sub-zero cooling $\left(-30^{\circ} \mathrm{C}\right)$ for double tempering treatment were studied using $650^{\circ} \mathrm{C}$ for the first tempering temperature and varying the temperature of the second cycle from 595 to $620^{\circ} \mathrm{C}$. The results reported in Figure 13 indicate that an intermediate cooling between the first and the second temper was beneficial for the reduction of hardness, especially for Heat B, thus confirming Gooch's suggestions [12].

Moreover, a final sub-zero treatment-which is expected to partially destabilize retained austenite-induced an increase in hardness, especially for Heat B (as shown in Figure 14).

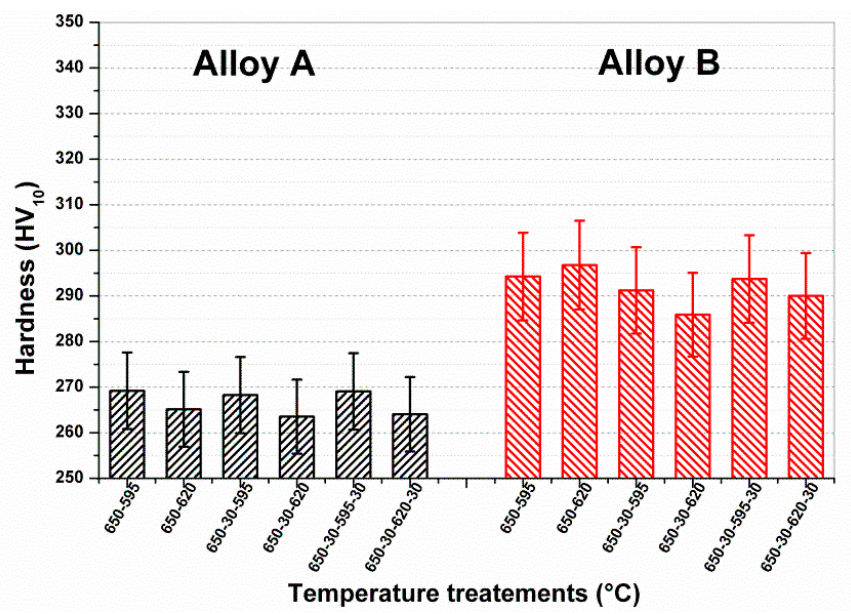

Figure 14. Hardness values for Heat $\mathrm{A}$ and Heat $\mathrm{B}$ following double tempering treatments with intermediate and final sub-zero $\left(-30^{\circ} \mathrm{C}\right)$ cooling.

\section{Discussion}

Despite similar chemical compositions and almost similar $\mathrm{Cr}_{\mathrm{eq}} / \mathrm{Ni}_{\mathrm{eq}}$ ratios of Heats $\mathrm{A}$ and $\mathrm{B}$, their responses to heat treatments were rather different. It is apparent that a significant reduction of hardness below the NACE limit (23 HRC) could be accomplished only for Heat A, whereas Heat B remained hard while also adopting the double tempering strategy recommended by NACE standards.

In order to obtain significant hardness reductions after tempering, the as-quenched martensite matrix should recover at high temperatures, allowing the retention of soft austenite islands without destabilization to virgin martensite. For the industrial heats studied, two major difficulties are presented. The first difficulty is to obtain significant volume fractions of stable retained austenite at room temperature, potentially as a result of the relatively high Ms values measured (Figure 2). The second difficulty is an intrinsic instability of reversed austenite formed at a temperature that favors the transformation to virgin martensite during cooling and limits the hardness reduction after tempering in the final product.

The stability of reversed austenite decreased during tempering as consequence of solute partitioning of $\gamma$-stabilizer elements (especially $\mathrm{Ni}$ and $\mathrm{C}$ ). As the tempering temperature increases, the volume fraction of reversed austenite increases and the consequent solute redistribution is no longer able to stabilize the $\gamma$ phase on cooling. This aspect is believed to be critical for $13 \mathrm{Cr}-4 \mathrm{Ni}-(\mathrm{Mo})$ industrial heats, which are characterized by relatively low carbon and nickel contents as compared to other supermartensitic alloys [6]. Moreover, alloying with molybdenum (0.5\%) reduces carbon diffusion towards reverted austenite islands, thus further limiting stabilization of reverted austenite and lowering kinetics for martensite recovery. Molybdenum is effective in decreasing the diffusion coefficient of elements such as carbon and sulfur within ferritic/martensitic structures, because of its strong affinity for those elements [20,21]. Loveless et al. [22] worked with $13 \mathrm{Cr} 4 \mathrm{Ni}$ alloys, finding that variants containing molybdenum presented increasing difficulties for hardness reduction through tempering. 
Additionally, it was observed that the retained austenite in these alloys was rather unstable. As demonstrated by the results reported in Figure 14, there is an apparent destabilization effect of sub-zero cooling for Heat B. This aspect is believed to be important for mechanical components that work at low service temperatures and/or under manufacturing and service strains, since a loss in toughness and in corrosion resistance may be envisaged.

Under these circumstances, limiting the formation of reversed austenite is believed to be useful during tempering, and can be accomplished by increasing the $\mathrm{Ac}_{1}$ critical temperature of the alloy as much as possible. This consequently allows for the recovery of the as-quenched microstructure at higher temperatures without the detrimental effect of austenite destabilization and the formation of virgin martensite upon cooling.

For example, Heats $\mathrm{A}$ and $\mathrm{B}$ appear different for experimental $\mathrm{Ac} \mathrm{c}_{1}$ and Ms temperatures, with both temperatures being higher for Heat $\mathrm{A}\left(\mathrm{Ac}_{1}=620^{\circ} \mathrm{C}, \mathrm{Ms}=270^{\circ} \mathrm{C}\right)$ than for Heat $\mathrm{B}\left(\mathrm{Ac}_{1}=600^{\circ} \mathrm{C}\right.$, $\mathrm{Ms}=250^{\circ} \mathrm{C}$ ). These differences might be the consequence of higher carbon and nitrogen contents for Alloy B, with nickel and manganese contents of alloys being almost identical (Table 1). Therefore, more stringent control of carbon and nitrogen may be the key to controlling the final hardness of $13 \mathrm{Cr}-4 \mathrm{Ni}-(\mathrm{Mo})$ industrial heats.

A first attempt to verify these conclusions has been done with Heat C, reported in Table 4 .

Table 4. Chemical composition of the alloy C.

\begin{tabular}{ccccccccccc}
\hline Heat & $\% \mathrm{C}$ & $\% \mathrm{Si}$ & $\% \mathrm{Mn}$ & $\% \mathbf{P}$ & $\% \mathrm{Cr}$ & $\% \mathbf{M o}$ & $\% \mathrm{~S}$ & $\% \mathbf{N i}$ & $\mathbf{N}(\mathrm{ppm})$ & $\% \mathrm{Cr}_{\text {eq }} / \% \mathbf{N i}_{\text {eq }}$ \\
\hline $\mathrm{C}$ & 0.018 & 0.420 & 0.68 & 0.023 & 12.53 & 0.53 & 0.001 & 4.00 & 68 & 2.70 \\
\hline
\end{tabular}

The carbon content was reduced to $0.018 \% \mathrm{C}$, and the nitrogen content was reduced to $68 \mathrm{ppm}$. The predicted $\mathrm{Ac}_{1}$ temperature for Heat $\mathrm{C}$ is $670^{\circ} \mathrm{C}$, which is about $15^{\circ} \mathrm{C}$ higher than Heat $\mathrm{A}$. From this it would be possible to increase tempering temperature without the formation of large volume fractions of unstable reverted austenite. Heat $C$ was treated through double tempering at 665 and $615^{\circ} \mathrm{C}$. The final mechanical properties—averaged from seven different samples-gave the following results: YS $=583 \mathrm{MPa}$, UTS $=751 \mathrm{MPa}$, with hardness of $21.4 \mathrm{HRC}$. These results allow for the supposition that the reduction of both carbon level below $0.02 \% \mathrm{C}$ and nitrogen below $100 \mathrm{ppm}$ are effective in controlling the final hardness of $13 \mathrm{Cr}-4 \mathrm{Ni}-(\mathrm{Mo})$ with industrial heats below NACE recommendations ( $23 \mathrm{HRC}$ ), without an unacceptable loss of mechanical strength.

\section{Conclusions}

Control of the final mechanical properties of industrial $13 \mathrm{Cr}-4 \mathrm{Ni}-(\mathrm{Mo})$ heats has proven to be difficult when using double tempering treatments in accordance with NACE specifications.

From the results obtained here, this difficulty is mainly related to the quantity of austenite reversion that can form during tempering that-if it is not sufficiently stable — transforms into virgin martensite during cooling, thus limiting the effect of the tempering process.

This, in turn, is due to the relatively low $\mathrm{Ac}_{1}$ temperatures of industrial heats, with the associated formation of unstable reverted austenite at temperatures above $600{ }^{\circ} \mathrm{C}$.

Therefore, limiting the amount of austenite reversion is believed to be necessary while favoring the recovery of untempered martensite at tempering temperatures as high as possible, without allowing the formation of virgin martensite upon final cooling. Reduced carbon $(<0.02 \% \mathrm{C})$ and nitrogen $(<100 \mathrm{ppm})$ levels have proven effective in controlling the final hardness of $13 \mathrm{Cr}-4 \mathrm{Ni}-(\mathrm{Mo})$ industrial heats below NACE recommendations ( $23 \mathrm{HRC}$ ), without an unacceptable loss of mechanical strength.

Moreover, the retention of significant amounts of soft retained austenite at room temperature for $13 \mathrm{Cr}-4 \mathrm{Ni}-(\mathrm{Mo})$ alloys should be carefully considered, as this phase appeared to transform into martensite following a sub-zero treatment at $-30{ }^{\circ} \mathrm{C}$. This phenomenon could be detrimental for mechanical components working at low service temperatures and/or under service strains. 
Author Contributions: Massimiliano Buccioni and Angelo Donato performed all heat treatments; Gianfranco Lovicu carried out hardness tests, tensile tests, Gleeble tests and performed TEM studies together with Massimo De Sanctis; Alessandra Varone and Maria Richetta performed XRD; All the authors discussed the results and contributed in writing the paper.

Conflicts of Interest: The authors declare no conflict of interest.

\section{Nomenclature}

$\begin{array}{ll}\mathrm{Ac}_{1} & \text { Austenite transformation temperature } \\ \mathrm{Cr}_{\text {eq }} & \text { Chromium equivalent (percentage of ferrite stabilizing elements) } \\ \delta, \alpha^{\prime}, \gamma & \text { phases designation } \\ \mathrm{HB} & \text { Brinell hardness } \\ \mathrm{HV} & \text { Vickers hardness } \\ \mathrm{HR} & \text { Preliminary hot forging } \\ \mathrm{HRC} & \text { Rockwell hardness, C scale } \\ \mathrm{Ms} & \text { Martensite start temperature } \\ \mathrm{Mf} & \text { martensite finish temperature } \\ n & \text { Instantaneous strain-hardening coefficient } \\ \mathrm{Ni} & \text { Nickel equivalent (weight percentage of austenite stabilizing elements) } \\ \mathrm{OQ} & \text { Oil Quenched } \\ \mathrm{UTS} & \text { Ultimate Tensile Strength } \\ \mathrm{YS} & \text { Yield Strength }\end{array}$

\section{References}

1. Kondo, K.; Ueda, M.; Ogawa, K.; Amaya, H.; Hirata, H.; Takabe, H.; Miyazaki, Y. Alloy design of super $13 \mathrm{Cr}$ martensitic stainless steel (Development of uper 13Cr martensitic stainless steel for line pipe-1). In Proceedings of the Supermartensitic Stainless Steels 99 Conference, Belgian, Brussels, 27-28 May 1999; pp. 11-18.

2. Niederau, H.J. A New Low-Carbon 16Cr-5Ni Stainless Martensitic Cast Steel. In ASTM STP 756 Stainless Steel Castings; Behal, V.G., Melilli, A.S., Eds.; American Society for Testing and Materials: West Conshohocken, PA, USA, 1982; pp. 382-393.

3. Nakada, N.; Tsuchiyama, T.; Takaki, S.; Miyano, N. Temperature Dependence of Austenite Nucleation Site on Reversion of Lath Martensite. Mater. Sci. Forum 2010, 638-642, 3424-3429. [CrossRef]

4. Liu, Z.B.; Yang, Z.Y.; Liang, J.X.; Zhang, L.N.; Zhang, X.L. Precipitation behavior and transformation kinetics of reverted austenite in ultra-high strength stainless steel. Trans. Mater. Heat Treat. 2010, 31, 39-44.

5. Park, E.S.; Yoo, D.K.; Sung, J.H.; Kang, C.Y.; Lee, J.H.; Sung, J.H. Formation of reversed austenite during tempering of $14 \mathrm{Cr}-7 \mathrm{Ni}-0.3 \mathrm{Nb}-0.7 \mathrm{Mo}-0.03 \mathrm{C}$ super martensitic stainless steel. Met. Mater. Int. 2004, 10, 521-525. [CrossRef]

6. De Sanctis, M.; Lovicu, G.; Valentini, R.; Dimatteo, A.; Ishak, R.; Migliaccio, U.; Montanari, R.; Pietrangeli, E. Microstructural Features Affecting Tempering Behavior of $16 \mathrm{Cr}-5 \mathrm{Ni}$ Supermartensitic Steel. Metall. Mater. Trans. A 2015, 46, 1878-1887. [CrossRef]

7. Song, Y.Y.; Li, X.Y.; Yin, F.X.; Ping, D.H.; Li, Y.Y. Variation of the Reversed Austenite Amount with the Tempering Temperature in a Fe-13\%Cr-4\%Ni-Mo Martensitic Stainless Steel. Mater. Sci. Forum 2010, 650, 193-198. [CrossRef]

8. Song, Y.Y.; Li, X.Y.; Rong, L.J.; Ping, D.H.; Yin, F.X.; Li, Y.Y. Formation of the reversed austenite during intercritical tempering in a Fe-13\%Cr-4\%Ni-Mo martensitic stainless steel. Mater. Lett. 2010, 64, 1411-1414. [CrossRef]

9. Bilmes, P.D.; Solari, M.; Llorente, C.L. Characteristics and effects of austenite resulting from tempering of 13Cr-NiMo martensitic steel weld metals. Mater. Charact. 2001, 46, 285-296. [CrossRef]

10. Lovicu, G.; De Sanctis, M.; Valentini, R.; Dimatteo, A.; Ishak, R.; Migliaccio, U.; Montanari, R.; Pietrangeli, E. Influence of presence and stability of reverted austenite on mechanical properties of $16 \mathrm{Cr}-5 \mathrm{Ni}$ supermartensitic stainless steel after tempering treatment. Metall. Ital. 2013, 105, 29-35. 
11. Haynes, A.G. Some factors governing the metallurgy and voidability of $13 \% \mathrm{Cr}$ and newer $\mathrm{Cr}-\mathrm{Ni}$ martensitic stainless steels. In Proceedings of the Supermartensitic Stainless Steels '99, Brussels, Belgium, 27-28 May 1999.

12. Gooch, T.G. Heat treatment of welded $13 \% \mathrm{Cr}-4 \% \mathrm{Ni}$ martensitic stainless steels for sour service. Weld. J. 1995, 74, 213s-223s.

13. APN005 Gleeble System Application Note; Dynamic System Inc.: Poestenkill, NY, USA, 2001.

14. Colla, V.; De Sanctis, M.; Dimatteo, A.; Lovicu, G.; Valentini, R. Prediction of Continuous Cooling Transformation Diagrams for Dual-Phase Steels from the Intercritical Region. Metall. Mater. Trans. A 2011, 42, 2781-2793. [CrossRef]

15. American Society for Testing and Materials. ASTM E975 Standard Practice for X-ray Determination of Retained Austenite in Steel with Near Random Cryslalographic Orientation; ASTM: Philadelphia, PA, USA, 2003.

16. De Moor, E.; Föjer, C.; Clarke, A.J.; Penning, J.; Speer, J.G. Quench \& partitioning response of a Mo-alloyed $\mathrm{CMnSi}$ steel. In Proceedings of the New Developments on Metallurgy and Applications of High Strength Steels Conference, Buenos Aires, Argentina, 26-28 May 2008; The Minerals, Metals \& Materials Society: Warrendale, PA, USA, 2008; pp. 721-729.

17. Fisher, R.B.; Larson, J.A. Experience and some pitfalls in processing CA6NM. In Proceedings of the Transactions of the American Foundrymen's Society, AFS Annual Meeting, Chicago, IL, USA, 19-23 April 1982; pp. 103-113.

18. Sherman, E.T.; Nalbone, C.S.; Scott, W.D. Processing low-carbon CA6NM (steel) to meet NACE (National Association of Corrosion Engineers) hardness requirements. In Proceedings of the 28th Annual Conference, Technical Advances in Steel Castings, Coventry, UK, 24-25 May 1983; Steel Castings Research and Trade Associations: Sheffield, UK, 1983.

19. Gooch, T.G.; Woollin, P.; Haynes, A.G. Welding Metallurgy of Low Carbon 13\% Chromium Martensitic Steels. In Proceedings of the Supermartensitic Stainless Steels '99, Brussels, Belgium, 27-28 May 1999; pp. 188-195.

20. Wada, H.; Pehlke, R.D. Nitrogen solubility and nitride formation in austenitic Fe-Ti alloys. Metall. Trans. $B$ 1985, 16, 815-822. [CrossRef]

21. Akben, M.G.; Bacroix, B.; Jonas, J.J. Effect of vanadium and molybdenum addition on high temperature recovery, recrystallization and precipitation behavior of niobium-based microalloyed steels. Acta Metall. 1983, 31, 161-174. [CrossRef]

22. Loveless, R.W.; Smith, W.C.; Templeton, N.C. Mechanical Testing for Deformation Model Development, ASTM STP 765; ASTM: Philadephia, PA, USA, 1982; pp. 394-402. 